\title{
POSSIBILITIES TO IMPROVE THE THERAPY OF THE PATIENTS WITH URETERAL CONCRETIONS
}

\author{
Maksym Sabadash \\ Department of reconstructive and geriatric urology \\ State Institution Institute of Urology of the National Academy of Medical Sciences in Ukraine \\ $9 a$ V. Vynnychenko str., Kyiv, Ukraine, 04053 \\ maxsabadash@i.ua \\ Alexandr Shulyak \\ Department of reconstructive and geriatric urology \\ State Institution Institute of Urology of the National Academy of Medical Sciences in Ukraine \\ 9a V. Vynnychenko str., Kyiv, Ukraine, 04053 \\ avshulyak@hotmail.com \\ Pavel Chabanov \\ Department of neurourology \\ State Institution Institute of Urology of the National Academy of Medical Sciences in Ukraine \\ 9a V. Vynnychenko str., Kyiv, Ukraine, 04053 \\ 88188@i.ua
}

\begin{abstract}
The aim of the given study was to improve the results of treatment of patients with concretions of the upper third of the ureter.

Materials and methods. The clinical trial was carried out as a non-interventional open, controlled, in two groups of patients with baseline control. The inclusion criteria concerned the patients with concretions of the upper third of the ureter $0.7-0.9 \mathrm{~mm}$ in size, which had one session of an extracorporeal shock-wave lithotripsy (ESWL), and after the procedure the size of the concretions fragments was up to $3 \mathrm{~mm}$. The study involved 60 patients, all patients in the main group $(\mathrm{n}=30)$ were treated using phytotherapy, within 1 month starting with basic therapy under hospital conditions and continuing with preventative treatment in an outpatient setting. The control group ( $\mathrm{n}=30$ ) received baseline therapy (up to 10 days) at the stationary stage.

Results and discussion. In patients of the main group, fragments of concretions came out significantly faster, namely: in the main group, the fragments came out in 21 patients $(70.0 \%)$, while in the control group in 15 patients $(50.0 \%)(\mathrm{p} 1-\mathrm{p} 2, \mathrm{p}<0.05)$ to the $7^{\text {th }}$ day, and in the main group, the fragments came out in one patient more than 14 days, and in the control group - in 5 patients, $\mathrm{p}<0.05$. The "stone path" in the bottom third of the ureter was in 1 patient (3.3\%) of the main group and in 3 patients $(10.0 \%)$ in the control group $(\mathrm{p} 1-\mathrm{p} 2, \mathrm{p}<0.05)$. The "stone path" departure time in patients of the main group was 2 days, and in patients of the control group it was 4.1 days from the time of its formation ( $\mathrm{p} 1-\mathrm{p} 2, \mathrm{p}<0.05)$. Bacteriuria was observed in the main group on the 10th day $6.6 \%$ less relative to the control group.

Conclusion. At comparing the obtained results in patients of both groups in 1 month it was noted that high efficacy of the treatment was registered in $6(20 \%)$ patients of the main group and in 3 patients $(10 \%)$ of the control group ( $p<0.05)$, moderate efficiency was registered in $23(76.7 \%)$ patients of the main group and in $22(73.3 \%)$ patients of the control group respectively, low efficacy was registered in $1(3.33 \%)$ patient in the main group and $5(16.7 \%)$ patients of the control group $(\mathrm{p}<0,05)$, which points to the effectiveness of Urolesan capsules use in complex therapy of patients with concretions of the one third of ureter.
\end{abstract}

Keywords: urolithiasis disease, extracorporeal shock-wave lithotripsy, phytotherapy.

\section{Introduction}

The prevalence of urolithiasis disease (UD), among all urological diseases, is second after urinary tract infections $[1,2]$. Recently, this indicator in Ukraine increased 1.2 times, the number of patients reaches over 160 thousand people - this is 973.5 cases per 100000 adult population. The rates of prevalence increase are $0.16-0.22$, the frequency of UD reaches $30-45 \%$ of the total urological pathology. Mostly, young people of working age suffer from this disease, $70 \%$ of patients aging from 20 to 50 years old. The disease can occur with the acute or chronic pyelo- 
nephritis, frequent recurrence of UD (30-80\%), which, in turn, leads to renal failure, disability and mortality in patients [3].

UD etiology and pathogenesis have not been completely determined until now. Kidney stones genesis is divided into causal and formal. Causal focuses on etiological factors; formal explains physico-chemical conditions of the concretions formation and conditions promoting the stone formation process. The stone formation pathogenesis in kidneys is divided depending on the type of crystalluria, urine $\mathrm{pH}$, excretion of one or another type of mineral salts, urine and oxalic acids, their salts, sodium, ammonium, magnesium and other factors $[4,5]$.

In some cases, UD develops against the background of calcium increased excretion during systemic skeletal diseases and severe bone injuries. In case of purine metabolism disorders (gout), urolithiasis disease is often associated with it. Endogenous factors, such as drinking water, food, micronutrients or vitamins deficiency, as well as some drugs have a certain role in UD formation $[6,7]$.

Implementation of the extracorporeal shock-wave lithotripsy significantly improved the efficacy of UD therapy, in particular for concretions sized $>6 \mathrm{~mm}$; and nowadays, it is the most effective non-invasive method applied for UD treatment [8]. In the treatment of ureterolithiasis by the ESWL method, complications may occur that affect the duration and tactics of patient management in the postoperative period. After ESWL, formation of a "stone path" is observed in $7 \%$ of cases, one of the causes of which is fixation of the group of concretions fragments in a limited section of ureter with the development of its mucous membrane edema, herewith, more than $70 \%$ of the "stone path" are formed in the lower third of the ureter $[9,10]$.

It should also be mentioned that the concretions fragments after disintegration can not always come out quickly due to the change of urodynamics of the upper urinary tract, spastic reaction of the ureter after ESWL and micro injuries by the stones fragments of the ureter. A lot of drugs have been proposed for medical therapy and concretions removal. Nowadays, selective alpha adrenergic antagonists $(\alpha 1 \mathrm{~A}$ and $\alpha 1 \mathrm{D}), \beta$-receptor agonists ( $\beta 2$ and $\beta 3), 5$-HT3 receptor antagonists, prostaglandin and cyclooxygenase antagonists, phosphodiesterase inhibitors, potassium channel openers and calcium channel blockers, NO-donor and Ro-kinase inhibitors are considered to be agents that can cause ureter wall relaxation and thus contribute to the concretions fragments removal after ESWL [13, 14].

Modern tasks for medicinal specialists involved in the treatment of patients with urolithiatic disease are both preventative measures, as well as measures aimed at preventing of the stones formation, their removal, and prescriptions of remedies that promote the removal of stones fragments, after a non-invasive treatment, with the minimal risk of complications.

Recently, phytotherapeutic remedies are becoming increasingly popular in the treatment of many urological diseases. This mainly depends on their availability and relative safety, as well as their good tolerability. However, the role of phytotherapeutic remedies in the treatment of patients with urolithiatic disease, in particular with ureteral concretions after a non-invasive treatment, has not been adequately studied.

Ukrainian scientists developed a multicomponent drug Urolesan, capsules containing herbal extracts: 1 capsule contains urolesan thick extract with $10 \%$ moisture - $10.70 \mathrm{mg}$ (contains dry residue: wild carrot fruit (Fructi Dauci carotae) (1:1) - 1.84 mg (extractant ethanol $96 \%$ ), common hop cones (Strobuli Humuli lupuli) (1:1) - $6.33 \mathrm{mg}$ (extractant ethanol 96 \%), Oregano herb (Herba Origani vulgaris) (1:1) - 1.46 mg (extractant ethanol $96 \%)$ ); Peppermint oil - 7.46 mg; Fir needle essential oil $-25.50 \mathrm{mg}$.

Ethanol extract of wild carrot seeds shows antispasmodic, diuretic, bactericidal, and antiinflammatory effects.

Ethanol extract of hop cones is used for neurasthenia, insomnia, neuralgia, in liver diseases, spleen disorders, radiculitis and joint diseases. It has anti-ulcer, estrogen-like, anti-inflammatory (especially for inflammatory diseases of kidneys, urinary and gallbladder), diuretic action. Remedies containing hop cones are traditionally used in the treatment of acute and chronic pyelonephritis, as a painkiller for renal stone disease and cystitis. 
Alcohol extract of oregano herb is used as expectorant, diaphoretic, anti-inflammatory, and sedative agent. Peppermint oil shows a sedative, antispasmodic, and choleretic effect.

Fir needle essential oil is a material for oil solutions and emulsions, containing fat-soluble vitamins, which, in combination with compounds of silicon, magnesium, and potassium, prevent crystalline formation, growth and aggregation of crystals of oxalate and calcium phosphate.

Urolesan has a wide range of pharmacotherapeutic effects, typical for standardized drugs of synthetic originn. The substantiation of the efficiency of the drug as a basic or complex therapy in the treatment of urolithiasis in acute and chronic infections of the bladder and kidneys is rather interesting, since the most common cases for the use of the drug are various forms of urolithiatic disease, as well as acute and chronic pyelonephritis.

Thus, all of the above-mentioned Urolesan properties determined the pathogenetic reasonableness of its use during the study in area of the treatment of patients with concretions of the upper third of the ureter after the session of extracorporeal ultrasound lithotripsy.

\title{
2. Aim of research
}

The am of the given study was to estimate efficiency and safety of the use of Urolesan in patients with concretions of the upper third of the ureter after ESWL.

\section{Materials and methods}

The clinical trial was carried out as a non-interventional open, controlled, in two groups of patients with baseline control.

The inclusion criteria concerned: the patients aged 18 to 65 years; with diagnosis: urolithiatic disease, concretions of the upper third of the ureter (only $0.7-0.9 \mathrm{~mm}$ in size); efficiency of the first ESWL session (after the procedure the size of the concretions fragments was up to $3 \mathrm{~mm}$ ); informed written agreement of the patient to participate in the study.

The exclusion criteria were: increased sensitivity to any component of the drug; inefficiency of the first ESWL session or after the procedure the size of the concretions fragments was more than $3 \mathrm{~mm}$; participation in any other clinical trial; congenital malformations of the urinary and excretory system organs; active inflammatory process in the urinary tract; cardiovascular disease; diabetes; immunodeficiency states; pregnancy; neurogenic bladder disorders; disorders of the blood circulatory system; gastritis (except gastritis with secretory insufficiency); stomach ulcer and duodenal ulcer.

The study involved 60 patients, having inpatient and outpatient treatment and meeting the criteria for inclusion/exclusion. Patients were randomly divided in groups. All patients of the main group ( $\mathrm{n}=30)$ were prescribed Urolesan oral capsules, manufactured by PJSC "Kyivmedpreparat" for 1 capsule 3 times a day, within 1 month starting from basic therapy under a hospital conditions and continuing as preventative therapy in outpatient conditions. The control group $(n=30)$ had baseline therapy (up to 10 days) at the inpatient stage.

The following examination methods were used: collecting anamnesis; objective examination; general clinical tests of blood and urine; biochemical blood test; bacteriological analysis of urine with the definition of sensitivity to antibiotic drugs; sonography; survey and excretory urography or multispiral computer tomography.

Basic therapy included non-steroidal anti-inflammatory drugs, antispasmodics and antibiotic therapy. The total observation period for each patient was 6 months.

The treatment efficiency was evaluated for up to 35 days according to the following scheme.

\author{
High efficiency \\ - The period for the concretions fragments coming out was up to 3 days after ESWL session. \\ - Pain intensity according to the NRS* scale was $<3$ points** \\ - Inflammatory process elimination was up to 10 days \\ Moderate efficiency \\ - The period for the concretions fragments coming out was up to 7- 14 days after ESWL session. \\ - Pain intensity according to the NRS* scale was 4- 7 points** \\ - Inflammatory process elimination was up to 30 days
}




\section{Low efficiency}

- The period for the concretions fragments coming out was more than 14 days after ESWL session.

- Pain intensity according to the NRS* scale was $>7$ points**

- Inflammatory process elimination was more than 30 days

Note: *-Numerical Rating Scale (NRS) [13]; **-Up to 5 days after ESWL session

The drug tolerability was evaluated by the symptoms and subjective feelings, according to the patient's words and objective data obtained during the treatment. The dynamics of laboratory parameters, as well as the frequency of occurrence and the nature of adverse reactions also was considered.

The drug tolerability was evaluated in points by the following scale:

1 point - well (no adverse reactions);

2 points - satisfactorily (insignificant adverse reactions, but there is no need in the drug withdrawal);

3 points - unsatisfactorily (there is an unwanted side effect having a significant negative effect on the patient's condition and requires the drug withdrawal).

The data defined as efficacy and tolerability criteria were evaluated using the proposed scale, statistically processed and compared prior, during and after the treatment. On the basis of the obtained results, conclusions concerning the efficacy and safety of the drug were made. The Student's criterion ( $p$ ) was used to estimate the intergroup differences in attributes that have a continuous distribution. The critical level of reliability of the zero statistical hypothesis was 0.05 and was statistically significant in cases of $p<0.05$; at $p>0.05$ the difference was within the limits of statistical error.

\section{Results of research}

The complete concretion fragmentation to the fragments size less than $3 \mathrm{~mm}$ was achieved in all involved patients. The patients having more than one ESWL session were excluded from the study. The patients' complaints at admission were: pain syndrome, which was manifested by an attack of the renal colic on the part of obstructive stone concrement of the ureter in all $100 \%$ of the patients, but pain syndrome severity during the concretion admission after its fragmentation of between the groups was different (Table 1).

\section{Table 1}

Pain intensity in both groups of the patients according to the Numerical Rating Scale in different periods of observation.

\begin{tabular}{|c|c|c|c|c|c|c|c|c|}
\hline \multirow{3}{*}{$\begin{array}{l}\text { Pain intensity estimation by the Numerical } \\
\text { Rating Scale, (NRS) in the patients of both } \\
\text { groups at admission and after ESWL session. } \\
\text { Hospitalization terms }\end{array}$} & \multicolumn{8}{|c|}{ Pain intensity estimation by 10 -points scale } \\
\hline & \multicolumn{2}{|c|}{ 0 points } & \multicolumn{2}{|c|}{ 1-3 points } & \multicolumn{2}{|c|}{ 4-6 points } & \multicolumn{2}{|c|}{ 7-10 points } \\
\hline & $\begin{array}{l}\text { Main } \\
\text { group }\end{array}$ & $\begin{array}{l}\text { Control } \\
\text { group }\end{array}$ & $\begin{array}{l}\text { Main } \\
\text { group }\end{array}$ & $\begin{array}{l}\text { Control } \\
\text { group }\end{array}$ & $\begin{array}{l}\text { Main } \\
\text { group }\end{array}$ & $\begin{array}{l}\text { Control } \\
\text { group }\end{array}$ & $\begin{array}{l}\text { Main } \\
\text { group }\end{array}$ & $\begin{array}{c}\text { Control } \\
\text { group }\end{array}$ \\
\hline At admission & - & - & 6 & 7 & 9 & 9 & 15 & 14 \\
\hline $\begin{array}{l}\text { After ESWL } \\
\text { Day } 1\end{array}$ & 9 & 8 & 5 & 7 & 11 & 9 & 5 & 6 \\
\hline Day 3 & 9 & 11 & 7 & 7 & 4 & 8 & 2 & 4 \\
\hline Day 5 & 18 & 15 & 9 & 7 & $2^{*}$ & 5 & $1^{*}$ & 3 \\
\hline
\end{tabular}

Note: $*_{-}<0,05$ 
At inclusion, there were no reliably statistically significant differences between the two groups. The control of patients after ESWL was carried out according to sonography and $\mathrm{X}$-ray/CT scans.

The initial parameters of the patients in both groups are shown in Table 2.

Table 2

The initial parameters of the both groups of the patients

\begin{tabular}{|c|c|c|c|}
\hline Markers & Main group $(n=30)$ & Control group $(n=30)$ & Confidence level, $p$ \\
\hline $\begin{array}{l}\text { The patients } \\
\text { average age, years }\end{array}$ & $37.8 \pm 3.9$ & $38.2 \pm 5.2$ & $>0.05$ \\
\hline Number of women & $17(56.7 \%)$ & $16(53.3 \%)$ & $>0.05$ \\
\hline Concretion size, $\mathrm{cm}$ & $0.79 \pm 0.6$ & $0.78 \pm 0.5$ & $>0.05$ \\
\hline $\begin{array}{l}\text { Leukocyturia, } \\
\text { number of patients }\end{array}$ & $17(56.7 \%)$ & $19(63.3 \%)$ & $>0.05$ \\
\hline $\begin{array}{c}\text { Bacteriuria, } \\
\text { number of patients }\end{array}$ & $11(36.7 \%)$ & $12(40.0 \%)$ & $>0.05$ \\
\hline $\begin{array}{c}\text { Creatinine of } \\
\text { blood serum, } \mu \text { moles } / 1\end{array}$ & $73.7 \pm 6.4$ & $64.2 \pm 7.3$ & $>0.05$ \\
\hline Daily diuresis, $\mathrm{ml}$ & $1647 \pm 210$ & $1732 \pm 192$ & $>0.05$ \\
\hline Urine $\mathrm{pH}$ & $6.5 \pm 1.2$ & $5.2 \pm 1.0$ & $>0.05$ \\
\hline $\begin{array}{l}\text { Average number of } \\
\text { impulses per session, number }\end{array}$ & $1623 \pm 205$ & $1657 \pm 197$ & $>0.05$ \\
\hline
\end{tabular}

According to the urine bacteriological study in the main group, bacteriuria was observed in $11(36.7 \%)$ patients, in the control group in $12(40.0 \%)$ patients. The most commonly isolated pathogens in the titers $>10 * 4$ CFUs were: E. coli in $8(72.7 \% / 11)$ patients of the main group and $7(58.3 \% / 12)$ patients of the control group, in $2(18.2 \% / 11)$ of the patients in the main group and $3(10.0 \% / 12)$ patients of the control group Pr. Mirabilis was found, and Kl.pneumoniae was found in $1(9.1 \% / 11)$ patient of the main group and $2(16.7 \% / 12)$ patients in the control group. On the 30th day of the study, the pathogens in urine were not found in patients of the main group, and one patient of the control group had K1. Pneumonia. Antibiotic therapy was carried out empirically and according to the antibioticogram results. The data concerning urine bacteriological examination in various terms is displayed in Fig. 1.

After ESWL session, fragments of concretions in the main group came out up to 3 days in $6(20.0 \%)$ patients, in the control group in $3(10.0 \%)$ patients $\mathrm{p}<0.05$; up to 7 days in the main group came out in $15(50.0 \%)$ patients, in the control group in $12(40.0 \%)$ patients $\mathrm{p}<0.05$; up to 14 days in the main group came out in $1(3.3 \%)$ patient, in the control group in $5(16.7 \%)$ patients $\mathrm{p}<0.05$ (Table 3).

group, the fragments came out in 21 patients $(70.0 \%)$, while in the control group in 15 patients $(50.0 \%)(\mathrm{p} 1-\mathrm{p} 2, \mathrm{p}<0.05)$ to the $7^{\text {th }}$ day, and in the main group, the fragments came out in one patient more than 14 days, and in the control group - in 5 patients, $\mathrm{p}<0.05$.

The "stone path" in the bottom third of the ureter was in 1 patient $(3.3 \% / 30)$ of the main group and in 3 patients $(10.0 \% / 30)$ in the control group $(\mathrm{p} 1-\mathrm{p} 2, \mathrm{p}<0.05)$, the period of the "stone path" coming out in the patient of the main group was 2.2 days, and in the patients of the control 
group 4.1 days from the moment of its formation ( $\mathrm{p} 1-\mathrm{p} 2, \mathrm{p}<0.05)$, that confirms the efficiency of the Urolesan remedy in treatment of the patients with urolithiatic disease.

The data concerning the normalization of urine in the patients of both groups are shown in Table 4.

Table 3

Duration of the concretions fragments coming out after ESWL session in the patients of both groups

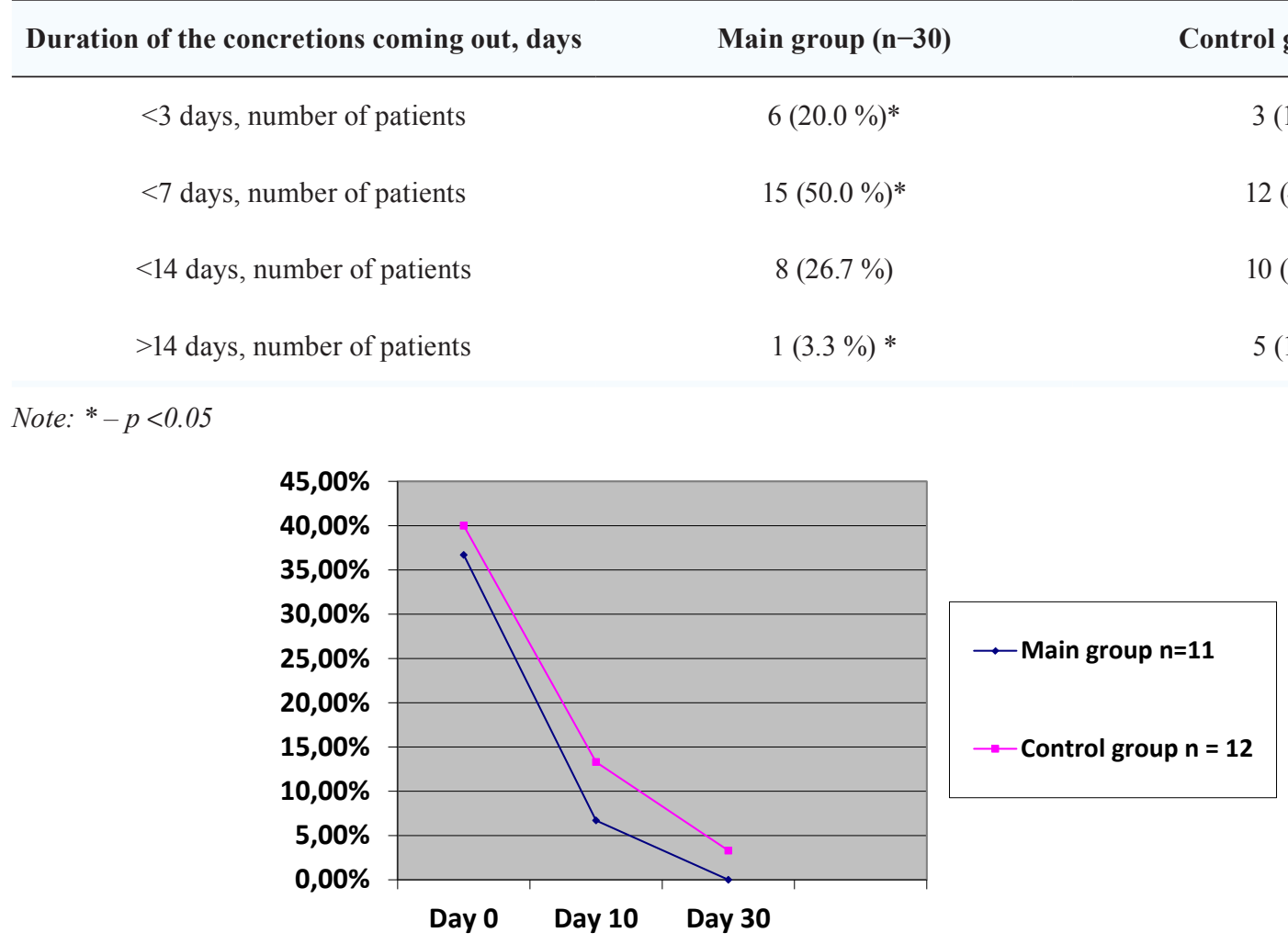

Fig. 1. Urine bacteriological examination markers in patients of both groups

Table 4

Terms of the normalization of general urine analysis markers in the patients depending on the therapy scheme

Normalization of the general urine analysis markers

Research groups

$10^{\text {th }}$ day

$3^{\text {th }}$ day

\begin{tabular}{ccccc} 
& abs. & $\mathbf{0}$ & abs. & \% \\
\hline Main group $(\mathrm{n}=30)$ & 19 & 63.3 & 28 & 93.4 \\
Control group $(\mathrm{n}=30)$ & 18 & 50.0 & 22 & $73.3^{*}$
\end{tabular}

Note: $*-p<0.05$

The pathological changes elimination in the general urine analysis was registered on the $10^{\text {th }}$ day in 19 patients $(63.3 \%)$ in the main group and in 18 patients $(50.0 \%)$ in the control group, and leukocyturia statistically significant normalization on the 30th day observed in $93.4 \%$ of the patients in the main group in relation to $73.3 \%$ of patients in the control group $(p 1-p 2, p<0.05)$, which proves the expediency of phytotherapy. 


\section{Discussion of results of the study}

The intensity of the pain syndrome in patients of both groups did not differ at admission, but the best results were observed in the patients of the main group on the $3^{\text {rd }}$ day, and statistically significantly better markers were determined on day $5(\mathrm{p}<0.05)$.

Gaponenko A. D. and coauthors proved in their study that Urolesan reduce spasms and pain in the urinary tract. Besides, it reduces renal tissue swelling, increases diuresis, therefore, concrements or their fragments come out faster. Urolesan contains components that increase renal blood flow and stimulate the removal of urea and chlorides from the blood and lead to normal urine $\mathrm{pH}$, has anti-inflammatory and antimicrobial activity [15].

In our study, the statistical significance of changes in the following criteria between patients in the two groups is observed, namely: before the $7^{\text {th }}$ day, in the main group, the fragments came out in $21(70.0 \% / 30)$ patients, and in the control group in $15(50.0 \%)$ patients (p1-p2, $\mathrm{p}<0.05$ ), the fragments came out in one patient of the main group more than 14 days, and in 5 patients $(p<0.05)$ of the control group indicating the high efficiency of phytotherapy in patients of the main group.

According to OF. Miller data, concretions up to $4 \mathrm{~mm}$ come out independently in $95 \%$ of cases, without any complications. Concretions sized $>6 \mathrm{~mm}$, as a rule, are treated by active methods, but in some cases they can come out independently [16]. According to the recommendations of the European Association of Urology, patients with concretions sized up to $5 \mathrm{~mm}$ without any reasons for their active removal, are recommended to have conservative treatment (evidence level 1a) [17]. In such cases, MET (medically expulsive therapy) is used, which promotes the spontaneous coming out of concretions, but it should be stopped in case of complications (intolerable pain, infection, dysfunction of the kidneys) (evidence level 1a) [18]. Using meta analysis, it was proved that concretions came out quickly in patients who took alpha-adrenoblockers and calcium channel blockers [18].

However, the data from several recent well-planned randomized clinical trials did not shown the MET benefits in patients with ureteric stones [19, 20].

The effectiveness of the ESWL use in patients with ureteric stones, according to various authors, varies from $60 \%$ to $85 \%$ and depends on the localization, size, chemical composition, duration of the stone in the ureter and complications [21]. Although ESWL is the least invasive procedure with the lowest level of complications, ureterroroscopy is a minimally invasive method that achieves stone-free in the greatest number of cases (level of evidence 1a) [22].

One of the ureteric concretions ESWL complications is the "stone path" in the bottom third of the ureter, which was found in one patient in the main group and 3 patients in the control group, and the healing period of the "stone path" in the patient of the main group was 2.2 days, and in patients of the control group was 4.1 days from the moment of its formation, which confirms the efficiency of Urolesan in the treatment of patients with urolithiatic disease.

Coptcoat and coauthors indicate 3 types of the "stone path": the $1^{\text {st }}$ type is accumulation of sand and small (up to $2 \mathrm{~mm}$ ) fragments - is the most common type; the $2^{\text {nd }}$ type is intruded "leading fragment", and above it there is a cluster of sand and small (up to $2 \mathrm{~mm}$ ) fragments; the $3^{\text {rd }}$ type is accumulation of large fragments. It is evident that the emergence of Type 2 and Type 3 is due to the lack of concrete fragmentation [23].

Amino acids of medicinal herbs (which involved in biosynthesis, transport and increase the bioavailability of other groups of biologically active substances), including Methionine and Glutamic acid play a significant role in treatment of urolithiatic disease and inflammatory diseases of kidneys and bladder; they are included the finished drugs (of synthetic origin), even in standard therapy with phosphate type of stone formation [24]. Due to the presence of terpenoids and polyphenols of flavonoid nature, phytotherapeutic remedies have a mild sedative and antispasmodic effect, which is very important in concrements coming out.

The essential oils terpene components of various structures, as a part of Urolesan composition, reduce the severity of inflammatory processes, increase the kidneys and liver blood supply, show diuretic, choleretic, and bactericidal effect, as well as normalize the tone (reduce spasm) of 
smooth muscles of the upper urinary tract and gall bladder. By stimulating kidney and liver blood circulation, terpenoids cause an increase in urination and biliary excretion [25].

According to A. G Chuchalin and coauthors data (2011), herbal remedies, as well as synthetic retinol and alpha tocopherol are used to preserve the crystalloid stability of urine in standard therapy [26], which are included in the composition of Urolesan in their natural form (carotenoids, and fatty acid fraction tocopherols), which significantly increase their bioavailability and efficiency compared to synthetic analogues.

Normalization of the general analysis of urine parameters up to the $30^{\text {th }}$ day is better by $20 \%$ in patients of the main group than in patients of the control group. On the $10^{\text {th }}$ day, bacteriuria in the main group at $6.6 \%$ less than in the control group was observed.

For polyphenols, and in particular flavonoids (including anthocyanins, catechins), anti-inflammatory, capillary stabilizing, anti-oxidant types of action are proven. Vitamins, in particular, tocopherols [26], which enter the body with the fatty acid fraction and Urolesan herbal component, are also extremely important in reducing of the crystallization, increase and aggregation of calcium oxalate and calcium phosphate in urine. Pyridoxine promotes reduction in the oxalic acid synthesis and stimulates processes of its neutralization in liver [27].

A comparative analysis of the clinical and laboratory efficacy of the treatment of patients using ESWL for concretions in one third of the ureter showed that the normalization of the general analysis of urine parameters in the patients of the main group was faster than in patients in the control group.

Therefore, at comparing the results of both groups, it was noted that high efficacy of treatment was registered in $6(20 \%)$ patients of the main group and in $3(10 \%)$ patients of the control group $(\mathrm{p}<0.05)$, the moderate efficiency of the treatment was registered in $23(76.7 \%)$ patients of the main group and $22(73.3 \%)$ patients of the control group respectively, low efficiency was registered in $1(3.33 \%)$ patient of the main group and $5(16.7 \%)$ patients of the control group $(\mathrm{p}<0.05)$. However, for more accurate data and clarification of the indications and contraindications, the further studies of Urolesan, which demonstrated high efficacy and the absence of adverse effects, should be carried out.

No patient of the main group had side effects, so all patients of the main group had 1 point of Urolesan capsules tolerability.

\section{Conclusion}

1. In patients of the main group, the concretions fragments came out faster relative to the control group, namely before the $7^{\text {th }}$ day, in the main group, the concretions fragments came out in $21(70.0 \% / 30)$ patients, and in the control group in $15(50.0 \%)$ patients $(\mathrm{p} 1-\mathrm{p} 2, \mathrm{p}<0.05)$, more than 14 days concretions fragments came out in one patient $(3.3 \%)$ in the main group, and in $5(16.7 \%)$ patients in the control group $(\mathrm{p}<0.05)$. The "stone path" in the bottom third of the ureter was in 1 $(3.3 \% / 30)$ patient in the main group and in $3(10.0 \% / 30)$ patients in the control group $(\mathrm{p}<0.05)$.

2 . The use of herbal medicine helps to reduce pain syndrome. In the patients of the main group after the ESWL session of concretions in third part of the ureter: $7-10$ points according to the Numerical Rating Scale (NRS) on the fifth day was in one patient $(3.3 \%)$ in the main group, in $3(10.0 \%)$ patients in the control group $(\mathrm{p}<0.05)$.

3. Results of the study showed high efficience, safety and tolerability of Urolesan capsules, in the treatment of patients with the concretions in third part of the ureter after the ESWL session.

\section{References}

[1] Vozianov, S. O., Shulyak, O. V., Banyra, O. B. (2012). Urology. Lviv: Quart Publishing House, 521.

[2] Lopatkin, N. A., Trapeznikova, M. F., Dutov, V. V., Dzeranov, N. K. (2007). Distance shockwave lithotripsy: past, present, future. Urology, 6, 3-13.

[3] Aboumarzouk, O. M., Somani, B. K., Monga, M. (2012). Flexible ureteroscopy and Holmium: YAG laser lithotripsy for stone disease in patients with bleeding diathesis: a systematic review of the literature. International Braz j Urol, 38 (3), 298-306. doi: 10.1590/s1677-55382012000300002 
[4] Seitz, C., Liatsikos, E., Porpiglia, F., Tiselius, H.-G., Zwergel, U. (2009). Medical Therapy to Facilitate the Passage of Stones: What Is the Evidence? European Urology, 56 (3), 455-471. doi: 10.1016/ j.eururo.2009.06.012

[5] Cooper, J. T., Stack, G. M., Cooper, T. P. (2000). Intensive medical management of ureteral calculi. Urology, 56 (4), 575-578. doi: 10.1016/s0090-4295(00)00658-0

[6] Porpiglia, F., Destefanis, P., Fiori, C., Scarpa, R., Fontana, D. (2002). Role of adjunctive medical therapy with nifedipine and deflazacort after extracorporeal shock wave lithotripsy of ureteral stones. Urology, 59 (6), 835-838. doi: 10.1016/s0090-4295(02)01553-4

[7] Cervenakov, I., Fillo, J., Mardiak, J., Kopecny, M., Smirala, J., Lepies, P. (2002). Speedy elimination of ureterolithiasis in lower part of ureters with the al-blocker tamsulosin. International Urology and Nephrology, 34 (1), 25-29. doi: 10.1023/a:1021368325512

[8] Porpiglia, F., Ghignone, G., Fiori, C., Fontana, D., Scarpa, R. M. (2004). Nifedipine versus tamsulosin for the management of lower ureteral stones. The Journal of Urology, 172 (2), 568-571. doi: 10.1097/01. ju.0000132390.61756.ff

[9] Ivanov, D. D., Vozianov, S. O., Kushnirenko, S. V. et. al. (2014). Urolithiasis, dysmetabolic nephropathy, crystalluria. Kyiv, 36.

[10] Zanetti, G. (2011). Ureteral stones: SWL treatment. Arch Ital Urol Androl, 83 (1), 10-13.

[11] Kushnirenko, S. V. (2014). Crystalluria in the practice of family physician. Family medicine, 6, 36-38.

[12] American Association of Urology 2016 (2017). Guidelines on urolithiasis, EAU.

[13] Sagalevich, A. I., Derkach, I. A., Shaparenko, E. V., Loskutov, A. E. et. al. (2010). Minimal invasive methods of treatment of bilateral nephrolithiasis. Urology, 14, 260-262.

[14] Hsieh, C.-H., Yang, S. S.-D., Lin, C.-D., Chang, S.-J. (2014). Are prophylactic antibiotics necessary in patients with preoperative sterile urine undergoing ureterorenoscopic lithotripsy? BJU International, 113 (2), 275-280. doi: 10.1111/bju.12502

[15] Gaponenko, A. D., Dosta, N. I., Nitkin, D. M., Wooed, V. I., Lelyuk, V. Yu., Nenartovich, V. S. (2016). Possibilities of application of the drug Urolesan in the treatment of diseases of the urinary system. Medical News, 4, 16-21.

[16] Miller, O. F., Kane, C. J. (1999). Time to stone passage for observed ureteral calculi: a guide for patient education. The Journal of Urology, 162 (3), 688-691. doi: 10.1097/00005392-199909010-00014

[17] European Association of Urology 2016 (2017). Guidelines on urolithiasis, EAU.

[18] Pain Intensity Instruments. National Institutes of Health. Warren Grant Magnuson Clinical Center (2003). Available at: http://www.mvltca.net/presentations/mvltca.pdf

[19] Furyk, J. S., Chu, K., Banks, C., Greenslade, J., Keijzers, G., Thom, O. et. al. (2016). Distal Ureteric Stones and Tamsulosin: A Double-Blind, Placebo-Controlled, Randomized, Multicenter Trial. Annals of Emergency Medicine, 67 (1), 86-95. doi: 10.1016/j.annemergmed.2015.06.001

[20] Sun, X., He, L., Ge, W., Lv, J. (2009). Efficacy of Selective $\alpha 1 \mathrm{D}-B l o c k e r$ Naftopidil as Medical Expulsive Therapy for Distal Ureteral Stones. The Journal of Urology, 181 (4), 1716-1720. doi: 10.1016/ j.juro.2008.11.118

[21] Hollingsworth, J. M., Rogers, M. A., Kaufman, S. R., Bradford, T. J., Saint, S., Wei, J. T., Hollenbeck, B. K. (2006). Medical therapy to facilitate urinary stone passage: a meta-analysis. The Lancet, 368 (9542), 1171-1179. doi: 10.1016/s0140-6736(06)69474-9

[22] Sayed, M. A.-B., El-Taher, A. M., Aboul-Ella, H. A., Shaker, S. E. (2001). Steinstrasse after extracorporeal shockwave lithotripsy: aetiology, prevention and management. BJU International, 88 (7), 675-678. doi: 10.1046/j.1464-4096.2001.02435.x

[23] Coptcoat, M. J., Webb, D. R., Kellet, M. J. et. al. (1988). The steinstrasse: a legacy of extracorporeal lithotripsy? European Urology, 14, 93-95.

[24] Kiseleva, T. L., Smirnov, Yu. A., Blinkov, I. L., Dronov, M. A., Tsvetayeva, E. V.; Kiselevoy, T. L. (2010). A brief encyclopedia of modern phytotherapy with the basics of homeopathy. Moscow: Izd. Of Professional Association of Natural Therapists, 592.

[25] Kurkin, V. A. (2009). Fundamentals of phytotherapy. Samara: OOO «Ofort»; GOU VPO «SamGMUROszdrava», 963.

[26] Chuchalina, A. G., Belousova, Yu. B., Yasnetsova, V. V. (2011). The Federal Manual on the use of medicines (formular system). Vol. 7. Moscow: Echo, 956.

[27] Kiseleva, T. L., Karpeyeva, A. A. (1997). Medicinal herbal raw materials and drugs containing substances that enhance the secretion the function of the kidneys. Homeopathy and phytotherapy in the treatment of cardiovascular diseases. Vol. 2. Moscow: Mosgorpechat, 672-799. 